\title{
Answer to the letter "Complete clinical retention of sealant materials should not be contemplated as cut-off for clinical success". Braz Oral Res. 2016;30:e32. doi: 10.1590/1807-3107BOR-2016.vol30.0032
}

\author{
Daniela HESSE(a) \\ Clarissa Calil BONIFÁCIO(b) \\ Camila de Almeida Brandão \\ GUGLIELMI (a) \\ Carolina da FANCA ${ }^{(c)}$ \\ Fausto Medeiros MENDES(a) \\ Daniela Prócida RAGGIO(a) \\ (a) Universidade de São Paulo, School of \\ Dentistry, Department of Pediatric Dentistry, \\ São Paulo, SP, Brazil. \\ (b)ACTA - Pediatric Dentistry, Amsterdam, \\ Netherlands. \\ (c) Universidade de Pernambuco, Department \\ of Social Dentistry, Recife, PE, Brazil.
}

Declaration of Interests: The authors certify that they have no commercial or associative interest that represents a conflict of interest in connection with the manuscript.

Corresponding Author:

Daniela Hesse

E-mail:dani_hesse@hotmail.com

DOI: 10.1590/1807-3107BOR-2016.vol30.0057

\section{Dear Prof. Mickenautsch,}

Thank you very much for reading and analyzing our paper very carefully. We actually agree with you that retention of sealant materials cannot be contemplated as any cut-off for clinical success regarding caries prevention; therefore we would like to apologize for our mistake as we erroneously state, "the complete clinical retention of sealant materials should be contemplated as the cutoff for clinical success" and cite your paper as reference to support it. ${ }^{1}$

Although we acknowledge that the prevention/arrestment of caries is the most important clinical outcome, other parameters should also be considered when selecting a dental material. The properties required of an ideal pit and fissure sealant include anticariogenicity, biocompatibility, good marginal integrity and retention rate. ${ }^{2}$ Among those properties, the longevity of the sealant material plays an important role in the clinical setting, ${ }^{3}$ as it can guide the clinician with regard to the choice of different materials available. Additionally, a satisfactory goal for the clinicians might be to seal the pits and fissures with the material that presents higher retention rates, protecting the sealed teeth for the first few years after eruption when the risk of caries can be higher. ${ }^{4,5}$

Therefore, we considered only fully retained sealants as successful in this trial, as our aim was to investigate the clinical retention of a lowcost glass ionomer cement (GIC) Maxxion R (FGM) after a short period of time (12 months). This GIC costs less than 25\% of the price of Fuji IX (GC corp) or Ketac Molar Easymix (3M ESPE), factor that could enable the use of this GIC for public healthcare in deprived areas. However, there were no preview reports on the survival rate of this material as pit and fissure sealant. Our results showed that the high-cost GIC brand (Fuji IX) presented a 2-fold-more-likely-to-survive than the lowcost brand after the first year of evaluation. ${ }^{6}$ So, the information of retention rate of this material can assist the clinician when selecting dental materials on a daily basis. We kept following these molars, not only evaluating the retention but also the caries incidence, data that will be published soon. 


\section{References}

1. Mickenautsch S, Yengopal V. Validity of sealant retention as surrogate for caries prevention - a systematic review. PLoS One. 2013;8(10):e77103. doi:10.1371/journal.pone.0077103

2. Waggoner WF, Siegal M. Pit and fissure sealant application: updating the technique. J Am Dent Assoc. 1996;127(3):351-61. doi:10.14219/jada.archive.1996.0205

3. Kühnisch J, Mansmann U, Heinrich-Weltzien R, Hickel R. Longevity of materials for pit and fissure sealing - results from a meta-analysis. Dent Mater. 2012;28(3):298-303. doi:10.1016/j.dental.2011.11.002
4. Subramaniam P, Konde S, Mandanna DK. Retention of a resin-based sealant and a glass ionomer used as a fissure sealant: a comparative clinical study. J Indian Soc Pedod Prev Dent. 2008;26(3):114-20. doi:10.4103/0970-4388.43192

5. Rogers HJ, Morgan AG, Batley H, Deery C. Why, what and how: caries control for erupting molars. Dent Update. 2015;42(2):154-6, 159.

6. Hesse D, Bonifácio CC, Guglielmi CAB, Franca C, Mendes FM, Raggio DP. Low-cost glass ionomer cement as ART sealant in permanent molars: a randomized clinical trial. Braz Oral Res 2015;29(1). doi:10.1590/1807-3107BOR-2015.vol29.0063 